\title{
A MODERNIDADE POR UM OLHAR NIETZSCHEANO NOS ESCRITOS DE JUVENTUDE
}

Modernity through a nietzschean look in the yough writings

Isabella Vivianny Santana Heinen *

Resumo: Este artigo objetiva desenvolver a questão da modernidade nietzscheana a partir de uma interpretação polissêmica. Isso é importante, pois, embora uma primeira concepção de modernidade surja da oposição entre o trágico e o científico, expressados pelo racionalismo socrático - otimista/dialético; e por Eurípides socratismo estético, tal como aparece desde $O$ nascimento da tragédia. Destacaremos, também, que Nietzsche elabora concepções acerca da modernidade, tendo em vista os aspectos da racionalidade, da verdade e da história, analisadas no período que caracteriza a sua fase de juventude. Assim sendo, a pesquisa torna-se importante não só por desenvolver uma análise teórica conceitual do autor, que oferece elementos teóricos e filosóficos que ajudam a pensar as questões da modernidade, mas ao mesmo tempo por querer aprender, com Nietzsche, outras posturas interpretativas diante do mundo que nos cerca.

Palavras-chave: modernidade; razão; verdade; história; Nietzsche

\begin{abstract}
This article aims to develop the issue of the Nietzschean modernity, from a polysemic interpretation. This is important because, although a first conception of modernity arises from the opposition between the tragic and the scientific, expressed by Socratic rationalism optimistic / dialectical; and by Euripides aesthetic socraticism, as it appears since The birth of tragedy. We will also point out that Nietzsche develops conceptions of modernity, considering the aspects of rationality, truth and history, analyzed in the period that characterizes his youth phase. This way, the search becomes important not only for developing a conceptual theoretical analysis of the author, which offers theoretical and philosophical elements that help to think the issues of modernity, but at the same time it becomes for the need of learning with Nietzsche about other interpretive postures towards the world around us.
\end{abstract}

Keywords: modernity; reason; truth; history; Nietzsche

* Mestra em Filosofia pela Universidade Federal do Pará. Professora substituta assistente do Instituto de Filosofia e Ciências Humanas da Universidade Federal do Pará. Email: isabellasantanaheinen@ gmail.com

\begin{tabular}{|c|c|l|l|l|l|}
\hline intuitio & $\begin{array}{c}\text { ISSN } \\
1983-4012\end{array}$ & Porto Alegre & Vol.8 $-\mathrm{N}^{\circ} .1$ & $\begin{array}{c}\text { Junho } \\
2015\end{array}$ & p.87-103 \\
\hline
\end{tabular}


Isabella Vivianny Santana Heinen

A modernidade por um olhar nietzscheano nos escritos de juventude

\section{I. $\mathrm{O}$ aspecto da racionalidade no $O$ nascimento da tragédia}

Nietzsche, em Ecce Homo (2003), elucida que delineou em sua obra Além do bem e do mal: prelúdio a uma filosofia do futuro (1992a) uma significativa crítica à modernidade. Mas, apesar de tê-la considerado como inscrição de sua crítica às ideias modernas, é evidente que praticamente todo seu percurso filosófico tenha sido uma tentativa de denunciar os valores da modernidade.

Conforme essa interpretação, observa-se que, desde $O$ nascimento da tragédia (1992b), uma abundância de noções converge para uma aversão de seu tempo, na medida em que, nessa obra, identifica o homem do século XIX como derivação do processo racional instaurado por Sócrates e continuado pelo racionalismo filosófico e pela doutrina cristã.

É, nesse ímpeto da fase de juventude, que Nietzsche pressupõe, com maior ênfase, sua análise da modernidade, ao esboçar com nitidez um dos aspectos designativos do período, isto é, a concepção de racionalidade filosófica. Por isso, em $O$ nascimento da tragédia, concebe a racionalidade como uma variante lógica do pensamento, que utiliza os conceitos como forma de apreensão e interpretação do mundo. E, de acordo com Nietzsche, é a partir do estabelecimento daquilo que se denomina "socratismo estético", ou seja, aquilo "cuja suprema lei soa mais ou menos assim: "Tudo deve ser inteligível para ser belo", como sentença paralela à sentença socrática: "Só o sabedor é virtuoso"." 1. Que se insere na arte uma visão racionalista, configurada pelo conceito, pela teoria, e pela lógica causal, isto é, em última análise, acaba por condicionar a expressão estética ${ }^{2}$ à inteligibilidade racional, oprimindo o saber trágico poético. O "socratismo estético" ${ }^{3}$, ao situar a arte trágica como irracional, desqualifica a expressão poética da existência, já que a metafísica racional toma a verdade e a essência como características principais.

Desse modo, para Roberto Machado (2001), O nascimento da tragédia pode ser interpretado a partir de três perspectivas: a primeira, no que tange à "crítica da racionalidade conceitual instaurada na

\footnotetext{
1 NIETZSCHE, F.W. O nascimento da tragédia ou helenismo e pessimismo. Trad. J. Guinsburg, São Paulo: Companhia das Letras, $1992 \mathrm{~b}$.

${ }^{2}$ Nietzsche argumenta no $O$ nascimento da tragédia, que a manifestação estética da tragédia grega poderia significar o vigor da expressão humana em seu esplendor, a partir da duplicidade apolínea e dionisíaca, impulsos inseparáveis em constante oposição ou mesmo reconciliação de forças. O primeiro, apolíneo ligado a forma, a ordem, a serenidade, ao equilíbrio, ao comedimento dos instintos, e, de certo modo, relaciona-se também as boas maneiras em sociedade, e as relações de conveniência. E, o segundo, dionisíaco configura-se pelas forças primordiais da vida, ao caos, a embriagues, a obscuridade, a afloração dos desejos, o rompimento dos obstáculos estabelecidos pela civilização, a liberação dos instintos, por intermédio do entorpecimento do vinho. Entende-se que as forças percebidas pelos impulsos, apolíneo e dionisíaco perpassam um processo de luta, de recriação, mostrando que os valores estão sempre passíveis ao novo, a mudanças, pois as forças de ambos se contrapõem ininterruptamente, promovendo alterações, rupturas, e criações sem os sobressaltos da culpa cristã. O O nascimento da tragédia trata a força dionisíaca como expressão que possibilita a agregação, a unidade entre constituições diferenciadas, e que, por conseguinte, reconduzem a natureza, a sua sensibilidade transmitida pela música enquanto reverberação do consolo metafísico, como possibilidade de valorização da vida, apesar de toda a sua tragédia.

3 NIETZSCHE, F.W. O nascimento da tragédia ou helenismo e pessimismo. Trad. J. Guinsburg, São Paulo: Companhia das Letras, 1992 b.
}

\begin{tabular}{|c|c|c|c|c|c|}
\hline intuitio & $\begin{array}{c}\text { ISSN } \\
1983-4012\end{array}$ & Porto Alegre & Vol.8 $-\mathrm{N}^{\mathrm{o}} .1$ & $\begin{array}{c}\text { Junho } \\
2015\end{array}$ & p.87-103 \\
\hline
\end{tabular}


filosofia por Sócrates e Platão" "; a segunda, no que diz respeito à "apresentação da arte trágica, expressão das pulsões artísticas dionisíacas e apolíneas, como alternativa à racionalidade" ${ }^{5}$; e, por sua vez, a terceira perspectiva, no que trata "a denúncia do mundo moderno como uma civilização socrática e a tentativa de descortinar o renascimento da tragédia ou da visão trágica do mundo em algumas manifestações culturais da modernidade" 6 .

Nesse sentido, em consonância com a interpretação de Machado, Nietzsche concebe a racionalidade como uma via lógica de conhecimento, que utiliza os conceitos como forma de apreensão do mundo. E, de acordo com Nietzsche, é a partir da formulação socrática da "estética racionalista" que se insere na arte uma visão racionalista, configurada pelo conceito, pela teoria, e pela lógica, isto é, em última análise, acaba por derivar a expressão estética da razão, oprimindo o saber trágico poético. A "estética racionalista”, ao situar a arte trágica como irracional, desqualifica a expressão poética do mundo, já que a metafísica racional toma a verdade e a essência como características principais.

Nietzsche, em $O$ nascimento da tragédia, pretendendo expressar as bases do que podemos denominar de uma nova teoria estética, assinala:

Teremos ganho muito a favor da ciência estética se chegarmos não apenas à intelecção lógica mas à certeza imediata da introvisão [Anschauung] de que o contínuo desenvolvimento da arte está ligado à duplicidade do apolíneo e do dionisíaco, da mesma maneira como a procriação depende da dualidade dos sexos, em que a luta é incessante e onde intervêm periódicas reconciliações ${ }^{7}$.

O filósofo argumenta que a manifestação estética da tragédia grega poderia significar a expressão humana em seu esplendor, a partir da duplicidade apolíneo e dionisíaco, impulsos inseparáveis em constante oposição ou mesmo reconciliação de forças. O primeiro, apolíneo, ligado a forma, a ordem, a serenidade, ao equilíbrio, ao comedimento dos instintos, e, de certo modo, relaciona-se também às boas maneiras em sociedade, e às relações de conveniência. E, o segundo, dionisíaco, configura-se pelas forças primordiais da vida, ao caos, à embriaguez, à obscuridade, à afloração dos desejos, ao rompimento dos obstáculos estabelecidos pela civilização, à liberação dos instintos, por intermédio do entorpecimento do vinho.

Entende-se que as forças percebidas pelos impulsos apolíneo e dionisíaco perpassam um processo de luta, de recriação, mostrando que os valores estão sempre passíveis ao novo e a mudanças, pois as forças de ambos se contrapõem ininterruptamente, promovendo alterações, rupturas e criações sem os sobressaltos da culpa cristã.

\footnotetext{
${ }^{4}$ MACHADO, R. Zaratustra - tragédia nietzscheana. Rio de Janeiro: Jorge Zahar Editor, 2001.

${ }^{5}$ MACHADO, R. Zaratustra - tragédia nietzscheana. Rio de Janeiro: Jorge Zahar Editor, 2001.

${ }^{6}$ MACHADO, R. Zaratustra - tragédia nietzscheana. Rio de Janeiro: Jorge Zahar Editor, 2001.

7 NIETZSCHE, F.W. O nascimento da tragédia ou helenismo e pessimismo. Trad. J. Guinsburg, São Paulo: Companhia das Letras, $1992 \mathrm{~b}$.
}

\begin{tabular}{|c|c|c|c|c|c|}
\hline intuitio & $\begin{array}{c}\text { ISSN } \\
1983-4012\end{array}$ & Porto Alegre & Vol.8 $-\mathrm{N}^{\mathrm{o}} .1$ & $\begin{array}{c}\text { Junho } \\
2015\end{array}$ & p.87-103 \\
\hline
\end{tabular}


O nascimento da tragédia trata da força dionisíaca como expressão que possibilita a agregação, a unidade entre constituições diferenciadas, e que, por conseguinte, reconduz a natureza, a sua sensibilidade transmitida pela música enquanto reverberação do consolo metafísico, como possibilidade de valorização da vida, apesar de toda a sua tragédia. Comenta Nietzsche:

[...] e o efeito mais imediato da tragédia dionisíaca é que o Estado e a sociedade, sobretudo o abismo entre um homem e outro, dão lugar a um superpotente sentimento de unidade que reconduz ao coração da natureza. O consolo metafísico - com que, como já indiquei aqui, toda a verdadeira tragédia nos deixa - de que a vida, no fundo das coisas, apesar de toda a mudança das aparências fenomenais, é indestrutivelmente poderosa e cheia de alegria, esse consolo aparece com nitidez corpórea como coro satírico, como coro de seres naturais, que vivem, por assim dizer indestrutíveis, por trás de toda civilização, e que, a despeito de toda mudança de gerações e das vicissitudes da história dos povos, permanecem perenemente os mesmos ${ }^{8}$.

Com efeito, compreende-se que, através da tragédia dionisíaca, se apura um novo conceito - o de unidade -, ainda que remontado pelos conceitos de Estado e sociedade, por si mesmos distintos e distantes. Isto é, a unidade pretendida entre estes termos associava-se à unidade desejada entre o apolíneo e o dionisíaco. Unidade que caracterizaria um forçoso consenso, pois o movimentar-se, próprio destes, seria limitado pelo que se deve ou não fazer, enquanto pertencente a uma civilização. Adverte Nietzsche:

Na verdade, não existe contraposição maior à exegese e justificação puramente estética do mundo, tal como é ensinada neste livro, do que a doutrina cristã, a qual é e quer ser somente moral, e com seus padrões absolutos, já com sua veracidade de Deus, por exemplo, desterra a arte, toda arte, ao reino da mentira- isto é, nega-a, reprova-a, condena-a. Por trás de semelhante modo de pensar e valorar, o qual tem de ser adverso à arte, enquanto ela for de alguma maneira autêntica, sentia eu também desde sempre a hostilidade à vida, a rancorosa, vingativa aversão contra a própria vida: pois toda a vida repousa sobre a aparência, a arte, a ilusão, a óptica, a necessidade do perspectivístico e do erro. O cristianismo foi desde o início, essencial e basicamente, asco e fastio da vida na vida, que apenas se disfarçava, apenas se ocultava, apenas se enfeitava sob a crença em "outra" ou "melhor" vida ${ }^{9}$.

Tendo como base essas acepções, Nietzsche explora o tema da civilização, construindo discussões severas acerca da tradição moral, civilizacional e estética, auspiciadas desde Sócrates, através de pressupostos dualistas, cultivados pela ideia de valor moral da tradição judaico-cristã ocidental, repelindo o dionisíaco e tomando o apolíneo enquanto impulso relacionado à instância do bem como finalidade da vida, rompendo a mediação vital entre Dionísio e Apolo. Nesse viés, a música retrataria um modo de expressão que identifica o elemento dionisíaco, que fez surgir a tragédia por meio da relação com o elemento apolíneo.

\footnotetext{
${ }^{8}$ NIETZSCHE, F.W. O nascimento da tragédia ou helenismo e pessimismo. Trad. J. Guinsburg, São Paulo: Companhia das Letras, 1992 b.

${ }^{9}$ NIETZSCHE, F.W. O nascimento da tragédia ou helenismo e pessimismo. Trad. J. Guinsburg, São Paulo: Companhia das Letras, 1992b.
}

\begin{tabular}{|c|c|l|l|l|l|}
\hline intuitio & $\begin{array}{c}\text { ISSN } \\
1983-4012\end{array}$ & Porto Alegre & Vol.8 $-\mathrm{N}^{\mathrm{o}} .1$ & $\begin{array}{c}\text { Junho } \\
2015\end{array}$ & p.87-103 \\
\hline
\end{tabular}


Segundo Jean Lefranc (2007), Nietzsche examina de maneira ampla as transposições ocasionadas pela música. Expõe-se:

Não devemos surpreender-nos com esta correspondência entre a música da Grécia Antiga e a da Alemanha moderna. Não se trata, como se supunha, de uma aplicação mais ou menos arbitrária da estética de Schopenhauer a domínios artísticos distantes. Já encontramos exemplos do que é para Nietzsche um verdadeiro método pelo confronto, ou melhor, pela interpretação recíproca do mais antigo e do mais moderno, um e outro esclarecendo-se, mesmo que seja por contraste ${ }^{10}$.

Compreende-se desde a Grécia Antiga até a Alemanha moderna e, para isso, a leitura que fez de Schopenhauer possibilitou uma postura contrassensual de avaliação. A música, sob esse aspecto, versa sobre os mais impensados campos, visto que expressa, em certa medida, o momento histórico, o pensamento de um povo, a linguagem de uma época, colocada em formas líricas, perpassando tanto os impulsos apolíneos, quanto dionisíacos. Descaracteriza um quadro contemplativo, para promover o novo, a construção.

Para Nietzsche, de acordo com Machado, Wagner foi "o grande motivador e inspirador das análises de Nietzsche" ${ }^{11}$, no sentido de reconhecer o ideal da época trágica grega, destacando a música como impulso dionisíaco que a faz vivaz, em função de sua música superar o entretenimento burguês e o amargo da moral cristã. Porém, sua concepção de Wagner é alterada, distanciando seu pensamento da vertente wagneriana e também schopenhaueriana, no que tange a teoria estética deste último.

Nietzsche, até antes de seu descontentamento com Wagner, concebia a música exprimida por este, como uma forma de eternização e reestruturação do espírito da música.

Aqui se faz agora necessário, com uma audaz arremetida, saltar para dentro de uma metafísica da arte, retomando a minha proposição anterior, de que a existência e o mundo aparecem justificados somente como fenômeno estético: nesse sentido precisamente o mito trágico nos deve convencer de que mesmo o feio e o desarmônico são um jogo artístico que a vontade, na perene plenitude de seu prazer, joga consigo própria. Difícil como é de se apreender, esse fenômeno primordial da arte dionisíaca só por um caminho direto torna- se singularmente inteligível e é imediatamente captado: no maravilhoso significado da dissonância musical; do mesmo modo que somente a música, colocada junto ao mundo, pode dar uma noção do que se há de entender por justificação do mundo como fenômeno estético. O prazer que o mito trágico gera tem uma pátria idêntica à sensação prazerosa da dissonância na música. $\mathrm{O}$ dionisíaco, com o seu prazer primordial percebido inclusive na dor, é a matriz comum da música e do mito trágico ${ }^{12}$.

\footnotetext{
${ }^{10}$ LEFRANC, Jean. Compreender Nietzsche. Trad. Lúcia M. E. Orth. 3 ed. Petrópolis, Rio de Janeiro: Vozes, 2007.

${ }^{11}$ MACHADO, R. Zaratustra - tragédia nietzscheana. Rio de Janeiro: Jorge Zahar Editor, 2001.

12 NIETZSCHE, F.W. O nascimento da tragédia ou helenismo e pessimismo. Trad. J. Guinsburg, São Paulo: Companhia das Letras, 1992 b.
}

\begin{tabular}{|c|c|c|c|c|c|}
\hline intuitio & $\begin{array}{c}\text { ISSN } \\
1983-4012\end{array}$ & Porto Alegre & Vol.8 $-\mathrm{N}^{\mathrm{o}} .1$ & $\begin{array}{c}\text { Junho } \\
2015\end{array}$ & p.87-103 \\
\hline
\end{tabular}


Segundo ele, o mito trágico e a música manifestavam o elemento dionisíaco, promovendo a possibilidade de justificação da vida, articulando, à vida, uma beleza impensável. Com o ressurgimento da tragédia expressada pela arte, se teria uma maneira de tornar a vida mais amena.

Em conformidade com Anna Cavalcanti (2011), o afastamento teórico de Wagner se estabeleceu em função do mesmo passar a valorizar pressupostos racionais, morais e políticos, reverberados na exposição de uma arte que exaltava valores nacionalistas de cunho moralizante. A expressão artística, nesse viés, é encarnada como uma ferramenta empenhada em estabelecer práticas morais com eficácia para a instituição de uma cultura nova - pretensão criticada por Nietzsche, justamente pela tentativa de colocar a arte como um mecanismo moral de reforma.

Em contraposição a Wagner, Nietzsche coloca a música como forma de combate à metafísica racionalista, pois a primeira não trabalha por conceito e não tem a função de comprovar logicamente sua intenção poética. Nietzsche sugestionava uma intervenção na racionalidade socrática do mundo moderno, a partir do destacamento da música e da arte trágica como possibilidade de um redirecionamento da visão da arte no mundo moderno.

O filósofo evidencia a posição de destaque da razão, contudo também valoriza a experiência estética, expressando o cerne da beleza, pois, segundo ele, para que os homens tenham a possibilidade de reflexão, de duvidar e de questionar, características próprias da filosofia, precisam vivenciar também experiências pautadas na arte, na beleza que a arte trágica pode proporcionar. Sem elas, a possibilidade do saber seria minimizada por um grau de concordância, no âmbito em que se deveria mensurar um conhecimento sem se ter entrado em contato com a harmonia proveniente de tudo que é belo.

Conforme Machado (1999), em oposição a essa valorização da tragédia, Sócrates, impelido por seu racionalismo, objetivava suprimir a arte trágica, por entender que esta não se tratava de um conhecimento seguro, justamente por se basear em sensações, que permitia ao espectador apenas sentir, e não entender através da inteligibilidade.

Nietzsche (1992b) observa que o sobressair da pura razão e sua imposição sobre a singeleza da natureza poderia dominar esta última, como um instrumento manipulável pelo homem através da razão, representada pela filosofia. E, com a separação desta da poesia, em certa medida, desqualifica-se a beleza sensível, por não estar no cerne do ideal racional. Destaca-se:

[...] devemos agora nos acercar mais da essência do socratismo estético, cuja suprema lei soa mais ou menos assim: "Tudo deve ser inteligível para ser belo", como sentença paralela à sentença socrática: "Só o sabedor é virtuoso" ${ }^{13}$.

${ }^{13}$ NIETZSCHE, F.W. O nascimento da tragédia ou helenismo e pessimismo. Trad. J. Guinsburg, São Paulo: Companhia das Letras, 1992b.

\begin{tabular}{|c|c|l|l|l|l|}
\hline intuitio & $\begin{array}{c}\text { ISSN } \\
1983-4012\end{array}$ & Porto Alegre & Vol.8 $-\mathrm{N}^{\mathrm{o}} .1$ & $\begin{array}{c}\text { Junho } \\
2015\end{array}$ & p.87-103 \\
\hline
\end{tabular}


De outro modo, segundo Nietzsche, Sócrates acentua em seu discurso que o belo precisa ser amado em sua configuração mais nobre e sublime, e que é através da razão que os homens produzem belezas vinculadas tanto à alma, quanto ao corpo, constituindo o universo, pois associados aquilo que é belo e bom, valorizam a verdade e as leis, permitindo aos homens alcançar a expressão de um ideal de beleza e também de conduta moral. Estes posicionamentos foram muito debatidos pelo filósofo alemão, por expressarem a típica visão da modernidade enquanto derivação da valorização racional socrática. Nessa perspectiva argumenta Roberto Barros (2011):

A modernidade evidencia-se para ele como época de percepção do fracasso do "projeto racional", explicitado pelo fato de este não alcançar seus objetivos afirmados como de primeira ordem. A verdade estável (diferenciada do mundo fenomênico, tomado então como transitório e aparente) e o seguro conhecimento de uma realidade estável e lógica são pressupostos baldados para Nietzsche. Por esse motivo, o racionalismo socráticoplatônico ocupa, sob a sua ótica, um patamar ainda inferior ao que a ciência relegou à arte: o de produtor de aparência sem conteúdo estético válido, em outros termos, de ilusão (Wahn) sem conteúdo vital ${ }^{14}$.

Em vista disso, a modernidade descreve a efetivação desse projeto racional, em que a concepção socrática, tal como a crença na eidetica de Platão, no que tange ao mundo verdadeiro e ao mundo aparente, valoriza um conhecimento fundamentado na lógica racional, objetivando o alcance da verdade como forma de segurança a estruturar o desenvolvimento na modernidade.

De acordo com Nietzsche, a partir da figura de Sócrates a idade trágica alcança seu fim, pois a idade da razão é chegada com ele. Sócrates passa a ser um opositor, um negador da cultura instintiva grega, um ser racional, que defende a razão como princípio de todas as coisas, e as paixões, bem como os instintos como algo inferior. É, no período socrático, que surge a boa forma, a boa conduta, o conceito de justiça, de bem, de sabedoria. Sócrates representa a figura do homem teórico, que determina, conceitua, critica, julga, argumenta. Como Nietzsche delineia:

Sócrates, o herói dialético no drama platônico, nos lembra a natureza afim do herói euripidiano, que precisa defender as suas ações por meio de razão e contra-razão, e por isso mesmo se vê tão amiúde em risco de perder a nossa compaixão trágica; pois quem pode desconhecer o elemento otimista existente na essência da dialética, que celebra em cada conclusão a sua festa de júbilo e só consegue respirar na fria claridade e consciência? Esse elemento otimista que, uma vez infiltrado na tragédia, há de recobrir pouco a pouco todas as suas regiões dionisíacas e impeli-las necessariamente à destruição até o salto mortal no espetáculo burguês? Basta imaginar as consequências das máximas socráticas: "Virtude é saber; só se peca por ignorância; o virtuoso é o mais feliz"; nessas três fórmulas básicas jaz a morte da tragédia. Pois agora o herói virtuoso tem de ser dialético; agora tem de haver entre virtude e saber, crença e moral, uma ligação obrigatoriamente visível; agora a solução transcendental da justiça de Ésquilo é

14 BARROS, R. de A. P. de. O ensinamento do Além-do-Homem como ideal estético de Nietzsche. Estudos Nietzsche, Curitiba, v. 2, n. 1, p. 99-119, jan./jun. 2011.

\begin{tabular}{|c|c|c|c|c|c|}
\hline intuitio & $\begin{array}{c}\text { ISSN } \\
1983-4012\end{array}$ & Porto Alegre & Vol. $-\mathrm{N}^{\circ} .1$ & $\begin{array}{c}\text { Junho } \\
2015\end{array}$ & p.87-103 \\
\hline
\end{tabular}


rebaixada ao nível do raso e insolente princípio da "justiça poética", com seu habitual deus ex machina ${ }^{15}$.

Observa-se que Sócrates introduz um ideal da razão, que regula os apetites promovendo uma existência racional. Com ele, também se instaura uma nova forma estética, fundamentada na consciência e na teoria, cuja colocação sobre o deus ex machina sugestiona uma espécie de otimismo dialético na tragédia, enquanto um instrumento adequado as questões nela apresentadas. Nietzsche explana que esse otimismo dialético, por sua vez, provoca uma ética otimista, sendo justamente em oposição a essa civilização socrática que pretende afrontar os preceitos da modernidade. Traça-se, como característica desse processo, o drama euripidiano. Sobre esse aspecto Nietzsche elucida,

O drama euripidiano é ao mesmo tempo uma coisa fria e ígnea, capaz de gelar e de queimar; é lhe impossível atingir o efeito apolíneo do epos, ao passo que, de outro lado, libertou-se o mais possível do elemento dionisíaco e agora, para produzir efeito em geral, precisa de novos meios de excitação, os quais já não podem encontrar-se dentro dos dois únicos impulsos artísticos, o apolíneo e o dionisíaco. Tais excitantes são frios pensamentos paradoxais - em vez das introvisões apolíneas - e afetos ardentes - em lugar dos êxtases dionisíacos - e, na verdade, são pensamentos e afetos imitados em termos altamente realistas e de modo algum imersos no éter da arte ${ }^{16}$.

Nesse sentido, compreende-se que o drama euripidiano desencadeia um movimento contrário às forças apolíneas e dionisíacas, pois a arte é desenvolvida como forma de contradição, e não como expressão da elasticidade do apolíneo e dionisíaco. Machado assinala que "Eurípedes se torna o poeta do racionalismo socrático: sua crítica da arte é o prolongamento da crítica socrática aos homens de sua época que por não terem consciência de seu ofício o exercem apenas por instinto." ${ }^{17}$. Isto é, Eurípedes é quem expressa de maneira aperfeiçoada a estética socrática e, com ele, a tragédia continua a ser desenvolvida, mas de forma diferenciada, pois traz um novo estilo artístico.

O caráter trágico, ligado aos instintos foi superado pelo caráter racional, pois há um descompromisso com o pensamento para que o espectador possa se identificar. Pois, Machado acrescenta:

Se algo só é bom se for consciente, se há relação necessária entre saber - virtude felicidade, o saber trágico, que é um saber inconsciente, se encontra necessariamente desclassificado. Em suma, pelo fato de ser impossível expressar conceitualmente - expor e comprovar racionalmente, logicamente - o trágico, Sócrates e Eurípedes negaram um saber como o de Ésquilo, que deve o que tem de melhor a uma "criação inconsciente" ${ }^{18}$.

${ }^{15}$ NIETZSCHE, F.W. O nascimento da tragédia ou helenismo e pessimismo. Trad. J. Guinsburg, São Paulo: Companhia das Letras, $1992 \mathrm{~b}$.

${ }^{16}$ NIETZSCHE, F.W. O nascimento da tragédia ou helenismo e pessimismo. Trad. J. Guinsburg, São Paulo: Companhia das Letras, $1992 \mathrm{~b}$.

${ }^{17}$ MACHADO, R. Nietzsche e a verdade. 2.ed. Rio de Janeiro: Rocco, 1999.

${ }^{18}$ MACHADO, R. Nietzsche e a verdade. 2.ed. Rio de Janeiro: Rocco, 1999.

\begin{tabular}{|c|c|c|c|c|c|}
\hline intuitio & $\begin{array}{c}\text { ISSN } \\
1983-4012\end{array}$ & Porto Alegre & Vol. $-\mathrm{N}^{\circ} .1$ & $\begin{array}{c}\text { Junho } \\
2015\end{array}$ & p.87-103 \\
\hline
\end{tabular}


Infere-se, de tal modo, que a arte para Eurípedes toma contornos estéticos racionalistas, dado que deseja promover um espetáculo, em que o observador possa compreender tudo, a partir unicamente de sua racionalidade. Desse modo, Eurípedes é o primeiro artista a enfatizar a questão da consciência. Assim, Sócrates, bem como Eurípedes, fomentam o rebaixamento da tragédia, exaltando o conhecimento e, por conseguinte, revelando uma predisposição a negar o dionisíaco. Instaura-se o otimismo teórico como uma possibilidade de regulação da existência, com talvez o intuito de corrigi-la. Barros (2011) pondera, "Distante do otimismo da metafísica, a perspectiva filosófica de Nietzsche não estabelece metas ou objetivos." ${ }^{19}$. De tal modo, a possibilidade de regulação da existência seria, então, denominada de otimismo teórico, reconhecido em nossa cultura como uma enorme dosagem de decadência na arte moderna, estabelecendo, ao contrário da pretensão nietzschiana, um conjunto de metas e objetivos.

Para se compreender, de modo mais claro, a questão socrática, na seção 18 de $O$ nascimento da tragédia, Nietzsche argumenta a situação do homem moderno, discutindo acerca do homem teórico, em que concebe uma contrariedade entre a condição pessimista, retratada pela tragédia, ou por uma interpretação trágica do mundo; e, o otimismo teórico, expresso pela racionalização e teorização socrática. Problemáticas trabalhadas por Nietzsche, a partir da seção 15 , circunstância em que o autor confere a Sócrates a categoria de homem teórico.

De acordo com Nietzsche, o artista deve se basear no inconsciente e no instinto como fonte de criação, porém, com Sócrates e Eurípedes, a tragédia foi rebaixada, em função da lógica, da razão. O filósofo acredita, com isso, que a racionalização, e a consequente diminuição do uso das sensações, são características do socratismo, constituindo-se, deste modo, a decadência, o declínio e a fraqueza do espírito. Posto isso, argumenta Spinks,

[...] é esta enfraquecida e restrita noção de vida - uma noção de vida definida por normas racionais e morais - que herdamos dos gregos e que constitui a base para nossas idéias modernas de valor moral e cultural. Agora temos idéias sobre a vida (como a democracia, o igualitarismo ou virtude moral) em vez de experimentar a força radical da vida, que foi mantida viva pelo espírito trágico grego. ${ }^{20}$

Nesse sentido, Sócrates se apresenta como um fomentador da verdade que pretende rebaixar a arte trágica, engendrando, na filosofia e na arte, a racionalidade conceitual, o raciocínio através da lógica e do conceito e, por sua vez, o elemento otimista, a dialética. Em lugar das pulsões e dos instintos, instaura-se a consciência.

19 BARROS, R. de A. P. de. O ensinamento do Além-do-Homem como ideal estético de Nietzsche. Estudos Nietzsche, Curitiba, v. 2, n. 1, p. 99-119, jan./jun. 2011.

${ }^{20}$ Tradução nossa. No original: "[...] it is this weakened and restricted notion of life - a notion of life defined by rational and moral norms - that we have inherited from the Greeks and that forms the basis for our modern ideas of moral and cultural value. Now we have ideas about life (such as democracy, egalitarianism or moral virtue) rather than experiencing the radical force of life that was kept alive by the Greek tragic spirit." SPINKS, Lee. Friedrich Nietzsche. New York: Routledge Taylor \& Francis e-Library, 2003.

\begin{tabular}{|c|c|c|c|c|c|}
\hline intuitio & $\begin{array}{c}\text { ISSN } \\
1983-4012\end{array}$ & Porto Alegre & Vol. $-\mathrm{N}^{\circ} .1$ & $\begin{array}{c}\text { Junho } \\
2015\end{array}$ & p.87-103 \\
\hline
\end{tabular}


Nietzsche defende, no $O$ nascimento da tragédia, a arte trágica, enquanto forma de uma arte superior para encarar a vida de maneira afirmativa, através das forças apolíneas e dionisíacas, expressas na música, apresentando Sócrates como um desqualificador desses elementos em conflito. Por outro lado, no livro A filosofia na era trágica dos gregos (2011) engendra uma análise das ideias de determinados pensadores pré-socráticos, que deram início à filosofia grega, salientando o surgimento da noção de princípio originário do mundo, bem como apresenta uma argumentação acerca do mundo, das causas e efeitos das coisas existentes neste. No capítulo II, observa que Sócrates é o último inscrito na cultura dos gênios, já que, em Platão, se situa uma gama de novas ideias, desenvolvendo outra tradição.

Nietzsche, neste momento, reitera sua crítica à cultura moderna, afirmando que a mesma encontrase naquilo que é comum, geral, e de baixa qualidade. Segue:

Uma época que sofre daquilo a que se chama cultura geral, mas que não tem cultura nenhuma, nem na sua vida tem unidade de estilo, nunca saberá o que fazer com a filosofia, mesmo que ela seja proclamada nas estradas e nos mercados pelo gênio da Verdade em pessoa. Numa época assim, ela será muito mais o monólogo erudito do passeante solitário, o roubo que o indivíduo faz por acaso, o segredo do quarto fechado ou a conversa inofensiva de velhos acadêmicos com crianças. Ninguém pode ousar cumprir a lei da filosofia em si, ninguém vive filosoficamente com aquela lealdade elementar que obrigava um Antigo, onde quer que estivesse e fosse o que fosse que fizesse, a comportar-se, como Estóico, se tinha jurado fidelidade à Stoa. Todo o filosofar moderno é restringido a uma aparência de erudição, politicamente e policialmente, por governos, por Igrejas, por academias, por costumes, por modas e pelas cobardias dos homens: fica-se pelo suspiro "se" ou pela constatação "era uma vez" ${ }^{21}$.

Em tal medida, a cultura moderna expressa uma grande aglomeração de ideias que orientam as classes, os sistemas, em que as condutas carregam consigo valores, hábitos, paixões provenientes de distintas ramificações, todos em devotado embate uns com os outros. O homem desse tempo agrega os mais variados conhecimentos e descobertas, porém seus instintos continuam a ser tolhidos e domesticados.

Desse modo, acentua que os gregos afirmaram sua filosofia na genialidade, numa grande exaltação do pensamento filosófico, enquanto que, na modernidade, o filosofar é simulado por um saber aprofundado, demonstrado na desenvoltura expressa pela erudição. Nietzsche propôs uma discussão a respeito da tradição erudita da filosofia na modernidade, cujas posturas apresentam, se não, uma repetição inflamada de envelhecidas ideias, que se limitam no cerne da mera teoria. O tempo da cultura na modernidade precisa ser pensado como uma maneira de reconfiguração do homem, enquanto um processo de criação e não de agregação de mero conhecimento. Por isso, a perspectiva da interpretação da modernidade, baseada em seu traço erudito, deve ser levantada enquanto implicação das múltiplas relações ocorridas no campo da linguagem como forma de aquisição de conhecimento e de constituição de

\footnotetext{
${ }^{21}$ NIETZSCHE, F.W. A filosofia na era trágica dos gregos. Trad. Gabriel Valladão Silva. Porto Alegre, RS: L\&PM,
} 2011.

\begin{tabular}{|c|c|l|l|l|l|}
\hline intuitio & $\begin{array}{c}\text { ISSN } \\
1983-4012\end{array}$ & Porto Alegre & Vol.8 $-\mathrm{N}^{\circ} .1$ & $\begin{array}{c}\text { Junho } \\
2015\end{array}$ & p.87-103 \\
\hline
\end{tabular}


valores. Corroborando nossa argumentação, Werle frisa: "A moral se revela como a manifestação mais patente da afirmação do homem [Mensch] como aquele que mede [Messende] ou que nomeia, pela linguagem, tudo que o cerca." 22. A linguagem, portanto, é impressa por meio de denominações que intentam exprimir uma verdade, um padrão geral de constituição; ou seja, uma maneira de afirmação do homem e do mundo fundamentada em valores morais.

\section{A representatividade da linguagem em Sobre a verdade e a mentira no sentido extra-moral}

Em Sobre a verdade e a mentira no sentido extra-moral (2008), Nietzsche assume uma postura desafiadora sobre o sistema constituído de sua época. Continua seu discurso a marteladas, repudiando o cenário moralizante em vigor, no âmbito do pessimismo romântico, ao passo em que coloca de forma vacilante a legitimidade da linguagem como demonstração acertada da realidade e, em certa medida, observa com escárnio a ambição humana de expressar o mundo por meio de metáforas. Porém, pode-se, então, pensar: o que faz ele próprio, em muitas ocasiões, se valer das metáforas? A resposta é simples: usa essa figura de linguagem para traduzir sua crítica a marteladas, e pensar a questão da linguagem, tendo como intermédio a interpretação, e não a determinação unívoca de nomeação das coisas.

Com base nos seus estudos filológicos, a investigação se amplia acerca do processo de proveniência e emprego das palavras, pois Nietzsche desenvolve sua análise criticando a ineficácia do conceito e, também, evidentemente, o seu teor filosófico, em vista da pretensão deste de dizer a verdade. Mas, acima do filósofo ou do filólogo, encontra-se o homem, e uma das distinções mais acentuadas é seu atrevimento, tanto de observar, quanto de ponderar sobre suas observações, retratando a necessidade do homem de se afastar da sua visão apequenada, para ver mais longe. Foucault reforça essa acepção nos escritos de Microfísica do poder (1995), no segundo capítulo Nietzsche, a genealogia e a história, salientando que é preciso tomar distância para se ver melhor, pois a proximidade é muito perigosa, por estar ligada a uma identidade, ou seja, ver no outro a si mesmo. Verifica-se que, no decorrer da história da filosofia, vários pensadores decidiram por essa ótica do afastar-se, a fim de mitigar a limitação dessa investigação.

Nietzsche, também, procurou observar com certo distanciamento, por isso possivelmente não refira sua filosofia à ideia de um princípio causador para o universo, desse modo não afirmando existir um momento de criação em que tudo se origina. Segundo ele, o homem não pode atribuir à natureza um começo ou um fim; ao contrário, o homem imerso em sua presunção não percebe sua própria

${ }^{22}$ WERLE, Marco Aurélio. Linguagem, filologia e interpretação na crítica de Nietzsche à moral e ao direito. Cadernos de filosofia alemã nº 11 | P. 111 - 126| JAN-JUN, 2008.

\begin{tabular}{|c|c|c|c|c|c|}
\hline intuitio & $\begin{array}{c}\text { ISSN } \\
1983-4012\end{array}$ & Porto Alegre & Vol.8 $-\mathrm{N}^{\mathrm{o} .1}$ & $\begin{array}{c}\text { Junho } \\
2015\end{array}$ & p.87-103 \\
\hline
\end{tabular}


insignificância. O distanciamento proposto por Nietzsche possibilita, justamente, uma análise menos egocêntrica, cuja percepção do homem ganha uma dimensão inferior, e sua notória inteligência é vista sem a vaidade da ideia de superioridade, já que ela passa a ser entendida como mais um atributo concernente à espécie humana, com o objetivo de auxiliar sua existência.

Justamente em função de sua existência, a necessidade do homem de se conservar vivo: viver em sociedade, alicerçando um acordo de paz, fundamentado em regras estabelecidas por ele próprio, prescrevendo de tal modo o que seja a verdade, e dando à linguagem uma atuação preponderante na designação das coisas, implicando em uma maneira de tornar as práticas uniformes a todos. "De fato, aquilo que daqui em diante deve ser a verdade é então fixado, quer dizer, é descoberta uma designação uniformemente válida e obrigatória das coisas, e a legislação da linguagem vai agora fornecer também as primeiras leis da verdade..." 23 .

Contudo, conforme a explanação de Nietzsche, em Sobre a verdade e a mentira no sentido extramoral, a linguagem serve para a nomeação e para o estabelecimento de relações entre o homem e as coisas, por meio do caráter metafórico, pois o homem toma um objeto pela primeira vez e, conferindo um nome, passa a acreditar em tal designação, encarando-a como verdadeira.

Enquanto ser racional, deve agora submeter seu comportamento ao poder das abstrações; não suporta mais ser levado pelas impressões súbitas e pelas intuições, mas generaliza em primeiro lugar todas as impressões em conceitos mais frios e mais exangues, a fim de atrelar neles a condução da sua vida e do seu agir. Tudo o que eleva o homem acima do animal depende dessa capacidade de fazer desaparecer as metáforas intuitivas num esquema ou, em outras palavras, dissolver uma imagem num conceito ${ }^{24}$.

Dessa maneira, a linguagem simplificaria as relações constituídas, por reduzir a grandiosidade e a importância das diferenças existentes em cada indivíduo. Por conseguinte, a descaracterização do que é individual engendra o conceito que, proveniente da presunção humana de abarcar a totalidade das coisas, através de sua inteligibilidade, cria formas de delimitar o que uma coisa é a partir do que ela apresenta de comum, porém, desconsiderando suas imperceptíveis diferenças. De acordo com Mosé (2012) é, desde a constituição democrática proveniente da criação da polis, que se estabelece a valorização da palavra, impetrada desde Sócrates. A modernidade, por sua vez, engendrada pela relação entre os homens, e pelo desejo instaurado através da linguagem de se alcançar a verdade, apresenta em sua configuração os reflexos da tentativa de dominação, como mecanismo de uma regulação da vida em sociedade.

${ }^{23}$ NIETZSCHE, F.W. Sobre verdad y mentira. Prólogo y Traducción de Alfredo Tzveibel. 1 ed. Buenos Aires: Miluno Editorial, 2008.

${ }^{24}$ NIETZSCHE, F.W. Sobre verdad y mentira. Prólogo y Traducción de Alfredo Tzveibel. 1 ed. Buenos Aires: Miluno Editorial, 2008.

\begin{tabular}{|c|c|l|l|l|l|}
\hline intuitio & $\begin{array}{c}\text { ISSN } \\
1983-4012\end{array}$ & Porto Alegre & Vol.8 $-\mathrm{N}^{\mathrm{o}} .1$ & $\begin{array}{c}\text { Junho } \\
2015\end{array}$ & p.87-103 \\
\hline
\end{tabular}


Nesse âmbito, Machado salienta que "Nietzsche negará a existência de um desejo natural de verdade através de uma concepção do intelecto como tendo um efeito específico de dissimulação" ${ }^{25}$. Ou seja, Nietzsche expressa que o homem na modernidade, tão arrogante de sua civilidade, de sua convivência em sociedade com os outros homens, coloca a verdade como baliza para o funcionamento da comunidade, desfavorecendo as suas intuições e sensações, e, por outro lado, favorecendo a negligência do homem moral, que tem por desígnio a verdade. Este filósofo não concebe a intuição em detrimento da razão, não sobrepõe uma extremidade a outra, porém oferece atenção à avidez de cada um em ter a administração da própria vida.

\section{O uso da história em Considerações extemporâneas}

Considerando o exposto, Nietzsche, em sua coletânea de quatro ensaios, intitulado Considerações extemporâneas (Considerações intempestivas) (2003), aborda na primeira consideração, David Strauss, o confessor e o escritor, que Strauss, ao aconselhar uma nova fé, a fim de revigorar a ética cristã, baseia-se em pressupostos racionalistas, condenando a vida por colocá-la condicionada à racionalidade do conhecimento inteligível. Na segunda consideração, Dos usos e desvantagens da história para a vida, Nietzsche expõe duramente a cultura, objetivando salientar como a história se apresenta em sua época. Em vista disso, adverte para o mau uso da história e os inconvenientes desta para a vida. Na terceira consideração, Schopenhauer como educador, procura transgredir os muros das instituições de ensino, explicada tanto pela sua compreensão de cultura, quanto pela desilusão da redução de sua carreira. E na quarta, e última consideração, Richard Wagner em Bayreuth, argumenta que o teatro de Bayreuth corresponderia ao palco perfeito para o ressurgimento da cultura. Podemos observar que Nietzsche estimula, através de suas considerações extemporâneas, a discussão acerca de questões como a cultura, a história, a educação, e a arte.

Mas, a título do que pretendemos nesse trabalho, destaca-se a singularidade com que Nietzsche empreende temas filosóficos, de modo a, constantemente, associar de maneira ampliada a cultura ao cenário histórico, para dar continuidade a suas investigações. Como vimos, a análise histórica está presente desde a primeira obra do filósofo, em que pesquisava sobre a cultura grega antiga. Já nas Considerações extemporâneas, que fala Dos usos e desvantagens da história para a vida, Nietzsche se detém na cultura moderna também numa perspectiva histórica. Sobre a questão da cultura Fernando Barros explica,

${ }^{25}$ MACHADO, R. Nietzsche e a verdade. 2.ed. Rio de Janeiro: Rocco, 1999.

\begin{tabular}{|c|c|c|c|c|c|}
\hline intuitio & $\begin{array}{c}\text { ISSN } \\
1983-4012\end{array}$ & Porto Alegre & Vol. $-\mathrm{N}^{\circ} .1$ & $\begin{array}{c}\text { Junho } \\
2015\end{array}$ & p.87-103 \\
\hline
\end{tabular}


Pois bem: cultura, para Nietzsche, não significa simplesmente erudição; significa de maneira bem diferente, o conjunto de todas as determinações da experiência humana consideradas, nos termos do filosofar nietzscheano, como produto de uma determinada atividade vital ${ }^{26}$.

Isto é, a cultura, para o filósofo da Basiléia, não se encontra vinculada estritamente ao que é considerado culto e erudito. Como já vimos antes em Sobre a verdade e a mentira no sentido extra-moral, esse processo de erudição é carregado de proposições moralizantes, concebido pelo uso da linguagem, pois, como a reiterar, destaca-se nas Considerações extemporâneas que a análise cultural relaciona-se a distintas perspectivas da constituição humana, cuja façanha de se saber muito, não é um fator preponderante para a identificação da cultura. Esta é compreendida como uma força, uma manifestação da existência humana, pautada em todas as formas de manifestação e compreensão do homem, seja ela pela linguagem, pela moral ou pela história. Ressaltam-se, com isso, discussões em contrariedade à objetividade reclamada pela ciência histórica, cuja pretensão de ser objetiva murcha a predisposição da ocorrência histórica de transmitir ao seu investigador uma vontade, que conduza a uma ação prática.

Nesse sentido, Nietzsche também direciona sua análise para o problema da cultura moderna nesta obra, nos indicando uma possível redenção, a saber, a arte trágica, que, com sua capacidade plástica, revigoraria a modernidade. Na Segunda Consideração extemporânea, o filósofo acrescenta:

Somente através de tal atuação verdadeira, a penúria, a miséria interior do homem moderno vira a tona e, no lugar daquela convenção e daquela mascarada amedrontadas e encobridoras, a arte e a religião poderão finalmente entrar em cena como as verdadeiras salvadoras, a fim de cultivar conjuntamente uma cultura que corresponda as verdadeiras necessidades, e não apenas ensine - como a cultura geral de hoje - a nos iludirmos quanto a estas necessidades e a nos tomarmos, por meio delas, mentiras ambulantes ${ }^{27}$.

Nietzsche contesta, conforme observado acima, um restabelecimento da arte, mediado unicamente através da metafísica e da própria ciência, que, segundo ele, são, da mesma maneira, instrumentos para desestimular a confiança na vida, não havendo nenhuma verdade em um caráter especifico que garanta legitimidade a um aspecto em detrimento de outro. A metafísica, a ciência, a moral e a religião ganham relevância nesse livro, enquanto qualidades capazes de enganar. Pois, uma cultura que engana ao estabelecer a ideia de que somente o caráter objetivo e científico são considerados verdadeiros,

\footnotetext{
${ }^{26}$ BARROS, F. de M. A maldição transvalorada: o problema da civilização em "O Anticristo" de Nietzsche. São Paulo: Discurso Editorial: Ijuí: Editora UNIJUÍ, 2002.

${ }^{27}$ NIETZSCHE, F.W. Segunda consideração intempestiva da utilidade e desvantagem da história para a vida. Trad. de Marco Antônio Casanova. Rio de Janeiro: Relume Dumará, 2003.
}

\begin{tabular}{|c|c|l|l|l|l|}
\hline intuitio & $\begin{array}{c}\text { ISSN } \\
1983-4012\end{array}$ & Porto Alegre & Vol.8 $-\mathrm{N}^{\mathrm{o}} .1$ & $\begin{array}{c}\text { Junho } \\
2015\end{array}$ & p.87-103 \\
\hline
\end{tabular}


providenciando um amontoado de saberes, desassociados de uma utilidade vital, constitui um discurso que tem como objetivo o desejo da sobreposição, por se identificar como verdade.

Nota-se, dessa maneira, uma configuração que incide em variadas perspectivas, na medida em que Nietzsche exibe um caráter histórico que se desenvolve sem a prescrição de um modelo verdadeiro, de uma rigorosidade sempre delineada em função de um passado, concebida para o emprego da vida. Tendo em vista que, quando a história exige seu embasamento numa verdade e numa objetividade que nada tem de objetiva, agencia um impedimento à afirmação da vida. Conforme assenta Céline Denat, "à objetividade é de fato tão pouco "objetiva" como as precedentes; ainda mais, ela apresenta um perigo dobrado: não atingindo uma verdade absoluta, ela promove um obstáculo ao crescimento da vida." ${ }^{28}$.

Nietzsche, o filósofo com argumentações extemporâneas, provocou o valor historicista, suas bases, sua utilidade, e seus métodos, suscitando que a história pode servir tanto para estagnar, como para nutrir a vida. Estagnar, no sentido de uma exacerbada valorização do passado; e nutrir, por apropriar-se sabendo de suas limitações, sendo justamente essas limitações a impulsionar o homem a criar e a inventar.

Por isso, a história não pode ter a função de enquadrar, de representar o todo, e de fazer com que o homem se reconheça, como uma maneira de identificação com os acontecimentos ocorridos no passado. Não se trata mais de situá-la na constância ou na continuidade, mas de repensá-la, verificando suas perspectivas e rupturas, que também implicam na cultura moderna.

\section{Considerações finais}

Nietzsche propunha à filosofia a partir de moldes antagônicos ao dos estabelecidos desde o racionalismo socrático. Ou seja, o filósofo em questão tratou de questões filosóficas com a mesma seriedade que geralmente a filosofia tradicional trata, porém se utilizando da via poética, não se limitando ao modo de conceituação próprio da filosofia.

Nesse âmbito, sem obedecer à racionalidade pretendida desde Sócrates, Nietzsche ressalta que “Aquele idílico pastor do homem moderno é apenas uma réplica da suma das ilusões culturais que para este último valem como natureza; o grego dionisíaco, ele, quer a verdade e a natureza em sua máxima força - ele vê a si mesmo encantado em sátiro.” ${ }^{29}$. Em tal medida, Nietzsche afasta-se dos princípios metafísicos da cultura ocidental e aproxima-se do deus Dioniso, contrapondo-se à ideia de conceito engendrado pela tradição socrática.

\footnotetext{
${ }^{28}$ DENAT, C. A filosofia e o valor da história em Nietzsche. Uma apresentação das Considerações extemporâneas. Cadernos Nietzsche $\mathrm{N}^{\circ}$ 26. São Paulo: Grupo de Estudos Nietzsche, 2010. Disponível em:< http://revistasofosunirio.files.wordpress.com/2012/03/cadernos-nietzsche-celine-denat.pdf $>$. Acesso em: 13 de Fev. de 2014, 14:23.

${ }^{29}$ NIETZSCHE, F.W. O nascimento da tragédia ou helenismo e pessimismo. Trad. J. Guinsburg, São Paulo: Companhia das Letras, 1992b.
}

\begin{tabular}{|c|c|c|c|c|c|}
\hline intuitio & $\begin{array}{c}\text { ISSN } \\
1983-4012\end{array}$ & Porto Alegre & Vol. $-\mathrm{N}^{\circ} .1$ & $\begin{array}{c}\text { Junho } \\
2015\end{array}$ & p.87-103 \\
\hline
\end{tabular}


Para Nietzsche, a ambição socrática de conceber a razão como causa exclusiva de uma presumível verdade resultou por restringir dogmaticamente a filosofia e a sua interpretação em uma representação convencional de conceitos, em que uma apreciação factual do mundo não se considera, porém, somente a consideração racional não contraditória do discurso.

Com isso, para efeito de compreensão da noção de modernidade na fase inicial do pensamento de Nietzsche, salienta-se que, no $O$ nascimento da tragédia, o filósofo, através da análise da figura socrática, interpreta o homem e a ópera de seu tempo como um processo grandioso de erudição: perspectiva básica para delinear sua crítica à modernidade. Por conseguinte, o filósofo aponta um possível "remédio" para a cultura moderna, sendo ele a música, expressão do apolíneo e do dionisíaco, enquanto manifestação da potência artística. Porém, observa-se de outro modo nas obras seguintes, a saber, Sobre a verdade e a mentira no sentido extra moral e Considerações extemporâneas, respectivamente, a promoção de uma discussão sobre o conceito de verdade, e a função da linguagem para a constituição da vida em sociedade, por normalmente se ampararem em pressupostos carregados de valores moralizantes. E, por sua vez, a última obra dessa fase versa acerca de sua concepção histórica, no que diz respeito à sua constante associação da cultura ao contexto histórico, a fim de fundamentar suas linhas interpretativas sobre a modernidade. Assim, cada uma dessas obras nos permite um olhar da modernidade, em que todas elas delineiam o posicionamento crítico e incisivo de Nietzsche a respeito da era moderna.

Destarte, a crítica da modernidade em Nietzsche, remete, por conseguinte, à crítica ao dogmatismo metafísico-racionalista de matriz socrático-platônica, por atribuir a ele o decisivo conflito entre valores, segundo a concepção dual empreendida na constituição ontológica do mundo. Essa concepção indica, de um lado, a realidade sensível referente à estrutura mundana, ao solo da aparência, da corporeidade, da imperfeição, e incorreção; de outro, incide na realidade inteligível, ligada à ideia de verdade e correção do mundo; tendo em vista que, no primeiro período de sua obra, a crítica da modernidade, e seus pressupostos, se desenvolveu por uma análise estética do mundo.

\section{Referências}

NIETZSCHE, F.W. Além do bem e do mal: prelúdio a uma filosofia do futuro. Trad. Paulo Cezar de Souza. São Paulo: Companhia das Letras, 1992a.

Companhia das Letras, $1992 \mathrm{~b}$. O nascimento da tragédia ou helenismo e pessimismo. Trad. J. Guinsburg, São Paulo: das Letras, 2003. Ecce homo. Como alguém se torna o que é. Trad. Paulo César de Souza. São Paulo: Companhia . Segunda consideração intempestiva da utilidade e desvantagem da história para a vida. Trad. de Marco Antônio Casanova. Rio de Janeiro: Relume Dumará, 2003.

Editorial, 2008. Sobre verdad y mentira. Prólogo y Traducción de Alfredo Tzveibel. 1 ed. Buenos Aires: Miluno 2011. . A filosofia na era trágica dos gregos. Trad. Gabriel Valladão Silva. Porto Alegre, RS: L\&PM,

\begin{tabular}{|c|c|l|l|l|l|}
\hline intuitio & $\begin{array}{c}\text { ISSN } \\
1983-4012\end{array}$ & Porto Alegre & Vol.8 $-\mathrm{N}^{\circ} .1$ & $\begin{array}{c}\text { Junho } \\
2015\end{array}$ & p.87-103 \\
\hline
\end{tabular}


A modernidade por um olhar nietzscheano nos escritos de juventude

BARROS, F. de M. A maldição transvalorada: o problema da civilização em "O Anticristo" de Nietzsche. São Paulo: Discurso Editorial: Ijuí: Editora UNIJUÍ, 2002.

BARROS, R. de A. P. de. O ensinamento do Além-do-Homem como ideal estético de Nietzsche. Estudos Nietzsche, Curitiba, v. 2, n. 1, p. 99-119, jan./jun. 2011.

CAVALCANTI, A. A. Nietzsche e Wagner: arte e renovação da cultura. Psicanálise \& Barroco em revista v.9, n.2: 101-116, dez. 2011.

DENAT, C. A filosofia e o valor da história em Nietzsche. Uma apresentação das Considerações extemporâneas. Cadernos Nietzsche $\mathrm{N}^{\circ}$ 26. São Paulo: Grupo de Estudos Nietzsche, 2010. Disponível em: $<$ http://revistasofosunirio.files.wordpress.com/2012/03/cadernos-nietzsche-celine-denat.pdf >. Acesso em: 13 de Fev. de 2014, 14:23.

FOUCAULT, M. Microfísica do Poder. Rio de Janeiro, Edições Graal, 1995.

LEFRANC, Jean. Compreender Nietzsche. Trad. Lúcia M. E. Orth. 3 ed. Petrópolis, Rio de Janeiro: Vozes, 2007.

MACHADO, R. Nietzsche e a verdade. 2.ed. Rio de Janeiro: Rocco, 1999.

. Zaratustra - tragédia nietzscheana. Rio de Janeiro: Jorge Zahar Editor, 2001.

MOSÉ, Viviane. O homem que sabe: do homo sapiens à crise da razão. 3 ed. Rio de Janeiro: Civilização Brasileira, 2012.

SPINKS, L. Friedrich Nietzsche. New York: Routledge Taylor \& Francis e-Library, 2003.

WERLE, Marco Aurélio. Linguagem, filologia e interpretação na crítica de Nietzsche à moral e ao direito. Cadernos de filosofia alemã no 11 |P. 111 - 126 | JAN-JUN, 2008.

Recebido em: 02/09/2014

Aprovado para publicação em: 23/07/2015

\begin{tabular}{|c|c|l|l|l|l|}
\hline intuitio & $\begin{array}{c}\text { ISSN } \\
1983-4012\end{array}$ & Porto Alegre & Vol.8 $-\mathrm{N}^{\mathrm{o}} .1$ & $\begin{array}{c}\text { Junho } \\
2015\end{array}$ & p.87-103 \\
\hline
\end{tabular}

